\title{
THE EFFECTS OF USING RECYCLED CONCRETE ON FATIGUE BEHAVIOR OF HOT MIX ASPHALT
}

\author{
Fereidoon MOGHADAS NEJAD ${ }^{\mathrm{a}}$, Ali Reza AZARHOOSH ${ }^{\mathrm{b}}$, Gholam Hossein HAMEDI ${ }^{\mathrm{a}}$ \\ ${ }^{a}$ Department of Civil and Environmental Engineering, Amirkabir University of Technology Tehran, Iran \\ ${ }^{b}$ Department of Civil Engineering, University of Guilan, Rasht, Iran
}

Received 02 Nov 2011; accepted 07 Mar 2012

\begin{abstract}
Fatigue cracking is the main form of structural damage in flexible pavements. Under the action of repeated vehicular loading, deterioration of the asphalt concrete materials in pavements caused by the accumulation and growth of the micro and macro cracks gradually takes place. The results of a laboratory study evaluating the fatigue properties of hot-mix asphalt (HMA) mixtures using indirect tensile fatigue test (ITFT) were investigated in this paper. The HMA mixtures containing $0 \%, 35 \%, 70 \%$, and $100 \%$ of recycling concrete aggregate (RCA) were plant prepared with one source of aggregate, limestone, and one type of binder, 60/70-penetration grade. In this paper, it is shown that the use of recycled concrete produced by crushing demolished concrete elements can increase the efficiency of asphalt mixes, reduce primary production costs and prevent much fullness of the recycled materials in the environment. It was found that replacing up to $100 \%$ of the virgin aggregate by RCA improved the fatigue properties of the asphalt mixtures.
\end{abstract}

Keywords: asphalt concrete, fatigue life, recycled concrete, indirect tensile test.

Reference to this paper should be made as follows: Moghadas Nejad, F.; Azarhoosh, A. R.; Hamedi, G. H. 2013. The effects of using recycled concrete on fatigue behavior of hot mix asphalt, Journal of Civil Engineering and Management 19(Supplement 1): S61-S68. http://dx.doi.org/10.3846/13923730.2013.801892

\section{Introduction}

Commonly encountered distresses such as rutting, fatigue and low temperature cracking due to increase in axle loads, traffic volume, environmental conditions and construction and design errors decrease the expected performance and service life of pavements (Sengoz, Topal 2005). The fatigue process occurs in three distinct stages. For instance, failure and fatigue cracking begin in step 1 , and cracks spread to other areas and reduce pavement resistance in step 2. Lastly, in step 3, sudden failure of the pavement is observed (Mariennfiel, Smiley 1994).

Various kinds of asphalt mixes with different properties show different fatigue behaviours. Several factors can be effective on the fatigue behaviour of asphalt mixtures, which include: asphalt layer thickness; type of loading (controlled strain and controlled stress); shape, frequency and period of rest in loading; properties of asphalt mixtures (asphalt content; air void; type, shape and gradation aggregates) and environmental conditions (temperature changes, wet and freezing) (Hafiang 2001).

To cope with these types of failures, various techniques have been developed. One such technique is the modification of hot-mix asphalt (HMA) by the utilization of recycling aggregate (such as recycling concrete aggregate which is obtained from construction and demolition waste (C\&D waste)). This technique can result in improved performance and service life of pavements.

Construction and demolition (C\&D) waste is generally defined as waste which arises from construction, renovation and demolition activities including land excavation or formation, civil and building construction, site clearance, demolition activities, roadwork, and building renovation (Shen et al. 2004; Tam, V., Tam, C. 2008).

Among the various types of construction materials, concrete was found to be the most significant component comprising approximately $75 \%, 70 \%, 40 \%$ and $70 \%$ collected from construction sites, demolition sites, general civil work and renovation work, respectively (Tam 2008). The use of recycled concrete aggregate (RCA) in civil works due to shortages of natural aggregate and landfill sites has been common in Europe and countries such as Japan and Australia for more than twenty years.

However, the use of RCA can offer the following benefits: 1) Economic advantages: RCA reduces primary production costs and the cost of waste storage; 2) Environmental benefits: the use of RCA preserves natural

Corresponding author: Fereidoon Moghadas Nejad

E-mail:moghadas@aut.ac.ir 
aggregates, reduces the overuse of landfills and reduces transportation effects and waste emissions; 3) The increased efficiency of asphalt mixes.

\section{Literature review}

With a view to saving bitumen and mineral substances and also for the purpose of preventing environmental pollution, the recyclable materials may be used without increasing the thickness of pavement structure (Cygas et al. 2011; Mucinis et al. 2009).

To date, few studies concerning the use of construction and demolition (C\&D) waste especially waste concrete as replacement aggregate in asphalt mixture and concrete have been conducted.

Perez et al. (2012) evaluates the possibility of designing hot asphalt mix road pavements using construction and demolition waste as coarse recycled aggregates. The percentages of recycled aggregates used in the mixtures were: $0 \%, 20 \%, 40 \%$ and $60 \%$. Cement and lime were used as fillers. The mixtures made with coarse recycled aggregates complied with the Marshall technical specifications for low volume roads. The mixtures also showed good resistance to permanent deformation evaluated by means of wheel tracking tests.

Another study evaluated the feasibility of using aggregate from recycled construction and demolition waste (RCDW) in pavement applications. A laboratory program was conducted by geotechnical characterization, bearing capacity and repeated load triaxial tests. The results show that the composition and the compactive effort influence on the physical characteristics of the RCDW aggregate. The compaction process has promoted a partial crushing and breakage of RCDW particles, changing the grain-size distribution and increasing the percentage of cubic grains. This physical change contributes to a better densification of the RCDW aggregate and consequently an improvement in bearing capacity, resilient modulus and resistance to permanent deformation. The results have shown that the RCDW aggregate may be utilized as coarse base and sub-base layer for low-volume roads (Leite et al. 2011).

Fonseca et al. (2011) assessed the use of construction and demolition (C\&D) waste as recycled aggregate (in particular crushed concrete) for the production of new concrete. This paper shows the main results of experiments to determine the influence of different curing conditions on the mechanical performance of concrete made with coarse recycled aggregate from crushed concrete. The properties analysed include compressive strength, splitting tensile strength, modulus of elasticity, and abrasion resistance. The general conclusion in terms of mechanical performance is that RAC is affected by curing conditions roughly in the same way as conventional concrete.

In a study conducted by Valeria (2010), an investigation of mechanical behaviour and elastic properties of recycled-aggregate concretes is presented. Several concrete mixtures were prepared by using only virgin aggre- gates (as reference), 30\% finer coarse recycled aggregate replacing fine gravel and 30\% coarse recycled aggregate replacing gravel. Results obtained showed that structural concrete up to $\mathrm{C} 32 / 40$ strength class can be manufactured by replacing $30 \%$ virgin aggregate with recycled-concrete aggregate. Moreover, a correlation between elastic modulus and compressive strength of recycled-aggregate concrete was found and compared to those reported in the literature. Finally, on the basis of drying shrinkage results, particularly if finer coarse recycled-concrete aggregate is added to the mixture, lower strains could be detected especially for earlier curing time.

Kou and Poon (2009) in other study, the fresh and hardened properties of self-compacting concrete (SCC) using recycled concrete aggregate as both coarse and fine aggregates were evaluated. Three series of SCC mixtures were prepared with $100 \%$ coarse recycled aggregates, and different levels of fine recycled aggregates were used to replace river sand. The SCC mixtures were prepared with $0,25,50,75$ and $100 \%$ fine recycled aggregates in Series I and II. The SCC mixtures in Series III were prepared with $100 \%$ recycled concrete aggregates (both coarse and fine). Different tests covering fresh, hardened and durability properties of these SCC mixtures were executed. The results indicate that the properties of the SCCs made from river sand and crushed fine recycled aggregates showed only slight differences. The feasibility of utilizing fine and coarse recycled aggregates with rejected fly ash and Class F fly ash for self-compacting concrete has been demonstrated.

The test results reported by Poon and Chan (2006) indicated that the use of $100 \%$ recycled concrete aggregate increased the optimum moisture content and decreased the maximum dry density of the sub-base materials compared to those of natural sub-base materials. The California bearing ratio (CBR) values (unsoaked and soaked) of the sub-base materials prepared with $100 \%$ recycled concrete aggregate were lower than those of natural sub-base materials. Nevertheless, the soaked CBR values for the recycled sub-base were greater than $30 \%$, which is the minimum strength requirement in Hong Kong.

Using the same methods, Khaled and Krizek (1996) found that RCA can be used as a base course in highway pavements if the recycled concrete aggregate is stabilized with as little as $4 \%$ cement and $4 \%$ fly ash by dry weight of the mix. Unfortunately, using RCA for base and subbase materials is associated with complications related to the high water solubility of RCA components, which can cause an increase of $\mathrm{pH}$ in nearby groundwater systems as well as possibly affecting the vegetation within the vicinity of the roads (Gilpin et al. 2004).

In a study by Paranavithana and Mohajerani (2006), it was found that all the volumetric properties (except the percentage of air voids), the resilient modulus and creep values of asphalt specimens containing RCA as coarse aggregates were relatively lower compared with 
the values found for similar specimens made with only fresh aggregates.

Also Wong et al. (2007) found that the use of recycled concrete as fillers/fines can increase the resilient modulus and reduce dynamic creep. The resilient modulus test was performed at two test temperatures $\left(25^{\circ} \mathrm{C}\right.$ and $40{ }^{\circ} \mathrm{C}$ ). At both test temperatures, the addition of RCA increased the resilient modulus, but a lower increase was obtained at the $40{ }^{\circ} \mathrm{C}$ test temperature.

Mill-Beale and You (2010) assessed the use of RCA at amounts of $25 \%, 35 \%, 50 \%$ and $75 \%$ of the total aggregate weight in asphalt mixes. The rutting potential using Asphalt Pavement Analyzer (APA), Dynamic Modulus (E*), Tensile Strength Ratio (TSR) for moisture susceptibility, Indirect Tensile Test (IDT) resilient modulus and the Construction Energy Index (CEI) are determined to evaluate the field performance suitability or otherwise of the mix. All 4 hybrid VA-RCA HMA mixes passed the minimum rutting specification of $8 \mathrm{~mm}$. The master curves for the hybrid mixes showed that the dynamic stiffness of the hybrid mixes was less than that of the control 4E1 mix, and it decreased when the RCA increased in the mix. In terms of moisture susceptibility, the tensile strength ratio increased with decreasing RCA; with only the $75 \%$ of RCA in the mix failing to meet the specification criterion. The compaction energy index proved that using RCA would save some amount of compaction energy. Finally, it has been recommended that a certain amount of RCA in hot mix asphalt (HMA) is acceptable for low-volume roads.

Also Lee et al. (2012) evaluated the pre-coated recycled concrete aggregate for hot mix asphalt. In this research, slag cement paste used for pre-coated RCA (PCRCA) with coating thickness of $0.25 \mathrm{~mm}, 0.45 \mathrm{~mm}$ and $0.65 \mathrm{~mm}$ to reinforce its ability is evaluated. The result shows that the PCRCA with coating thickness of $0.25 \mathrm{~mm}$ has the optimum coating paste volume for HMA mixture. The indirect tensile strength (ITS) test, moisture sensitivity test and wheel-track rutting test of HMA with substitution ratios of $25 \%, 50 \%, 75 \%$ and $100 \%$ PCRCA mixture are discussed. The results indicate that the properties of PCRCA have highly pores contents, absorption of water and asphalt contents. However, the physical properties of the PCRCA used as aggregate and test of HMA with PCRCA are within the range of the specification requirements.

\subsection{Objective}

The main objective of the research presented in this paper was to characterize the fatigue behaviour of HMA mixtures containing RCA in terms of gradation type, concrete replacement value and temperature. Fatigue life of each mixture was measured and the fatigue life prediction equation was obtained using the regression analysis. Fatigue behaviour of mixtures was compared to each other and the effect of each mixture parameter was investigated.

\section{Materials}

In the present study, the limestone aggregate was obtained from the mining of Aghkand in Guilan province, Iran. The physical properties of limestone are shown in Table 1.

Also, recycled concrete aggregates prepared from demolished buildings were not directly used in asphalt mixtures. Aggregates prepared from the early destruction of buildings were rather large; thus, after being transported to the laboratory, the aggregates were crushed by a crushing machine to produce aggregates with dimensions smaller than $25 \mathrm{~mm}$. Due to the presence of cement paste on the surface of the original natural aggregates, recycled concrete aggregates have different physical, chemical and mechanical properties than natural aggregates. The cement paste reduces the density and increases the water absorption capacity (Paranavithana, Mohajerani 2006). Limestone was used as fresh aggregate, and RCA was used as secondary aggregates.

Table 1. Physical properties of the aggregates

\begin{tabular}{lccc}
\hline \multicolumn{1}{c}{ Test } & Standard & Value & Specification limit \\
\hline $\begin{array}{l}\text { Specific gravity } \\
\text { (coarse agg.) }\end{array}$ & ASTM C 127 & & \\
\hline Bulk & & 2.612 & ----- \\
\hline SSD & 2.643 & ----- \\
\hline Apparent & 2.659 & ----- \\
\hline $\begin{array}{l}\text { Specific gravity } \\
\text { (fine agg.) }\end{array}$ & ASTM C 128 & & \\
\hline Bulk & & 2.618 & ----- \\
\hline $\begin{array}{l}\text { SSD } \\
\text { Apparent }\end{array}$ & & 2.633 & ----- \\
\hline $\begin{array}{l}\text { Specific gravity } \\
\text { (filler) }\end{array}$ & ASTM D 854 & 2.640 & ----- \\
\hline $\begin{array}{l}\text { Los Angeles } \\
\text { abrasion (\%) }\end{array}$ & ASTM C 131 & 25.6 & Max 45 \\
\hline $\begin{array}{l}\text { Flat and } \\
\text { elongated } \\
\text { particles (\%) }\end{array}$ & ASTM D 4791 & 9.2 & Max 10 \\
\hline $\begin{array}{l}\text { Sodium sulfate } \\
\text { soundness (\%) }\end{array}$ & ASTM C 88 & 2.56 & Max 10-20 \\
\hline $\begin{array}{l}\text { Fine aggregate } \\
\text { angularity }\end{array}$ & ASTM C 1252 & 46.65 & Min 40 \\
\hline
\end{tabular}

Table 2. Gradation of aggregates used in the present study

\begin{tabular}{|c|c|c|c|c|c|c|c|c|c|}
\hline Sieve (mm) & & 25 & 19 & 12.5 & 9.5 & 4.75 & 2.36 & 0.3 & 0.075 \\
\hline \multirow{2}{*}{ Passing (\%) } & A & - & 100 & 95 & - & 59 & 43 & 13 & 6 \\
\hline & $\mathrm{B}$ & 100 & 95 & - & 68 & 50 & 36 & 12 & 5 \\
\hline
\end{tabular}


The gradation of aggregates used in the present study (the median limits of ASTM specifications for dense aggregate gradation) is shown in Table 2. Two types of gradation were evaluated that include type A and B with a nominal maximum aggregate size (NMAS) of 19 and $25 \mathrm{~mm}$ respectively. An asphalt binder, 60/70-penetration grade obtained from Isfahan Petroleum Refineries was used as binder for mixture preparation. The properties of the asphalt binder are presented in Table 3 .

Table 3. Experimental results of $60-70$ penetration asphalt binder

\begin{tabular}{lcc}
\hline \multicolumn{1}{c}{ Test } & Standard & Result \\
\hline $\begin{array}{l}\text { Penetration }\left(100 \mathrm{~g}, 5 \mathrm{~s}, 25^{\circ} \mathrm{C}\right), \\
0.1 \mathrm{~mm}\end{array}$ & ASTM D5-73 & 64 \\
\hline $\begin{array}{l}\text { Penetration }\left(200 \mathrm{~g}, 60 \mathrm{~s}, 4^{\circ} \mathrm{C}\right), \\
0.1 \mathrm{~mm}\end{array}$ & ASTM D5-73 & 23 \\
\hline Penetration ratio & ASTM D5-73 & 0.36 \\
\hline Ductility $\left(25^{\circ} \mathrm{C}, 5 \mathrm{~cm} / \mathrm{min}\right), \mathrm{cm}$ & ASTM D113-79 & 112 \\
\hline Softening point, ${ }^{\circ} \mathrm{C}$ & ASTM D36-76 & 51 \\
\hline Flash point, ${ }^{\circ} \mathrm{C}$ & ASTM D92-78 & 262 \\
\hline Heating loss, $\%$ & ASTM D1754-78 & 0.75 \\
\hline Properties of the TFOT Residue & & \\
\hline $\begin{array}{l}\text { Penetration }\left(100 \mathrm{~g}, 5 \mathrm{~s}, 25^{\circ} \mathrm{C}\right), \\
0.1 \mathrm{~mm}\end{array}$ & ASTM D5-73 & 60 \\
\hline Specific gravity at $25^{\circ} \mathrm{C}, \mathrm{g} / \mathrm{cm}^{3}$ & ASTM D70-76 & 1.020 \\
\hline Viscosity at $135^{\circ} \mathrm{C}, \mathrm{cSt}$ & ASTM D2170-85 & 158.5 \\
\hline
\end{tabular}

\section{Experimental setup and procedure}

\subsection{Mix design}

In the current study, four asphalt concrete mixtures were investigated. The first mixture was an asphalt concrete mixture containing 100\% limestone aggregates, which was labelled as the control mix. Alternatively, in the other mixtures RCA was used as an aggregate. The mix design of the straight asphalt mixtures was conducted by using the standard Marshall mix design procedure with 75 blows on each side of cylindrical samples $(101.6 \mathrm{~mm}$ in diameter and $40 \mathrm{~mm}$ thick).

Marshall samples were compacted and tested by deploying the following standard procedures: bulk specific gravity (ASTM D2726), stability and flow test (ASTM D1559), and maximum theoretical specific gravity (ASTM D2041). Two series of Marshall specimens were fabricated. The first series of specimens contained various concentrations of binder to determine the optimal binder content. The second series was produced at the optimal binder content to evaluate the HMA mechanistic properties. For each aggregate blend and asphalt binder content, at least three samples were produced to determine the reproducibility of the results (ASTM 2000). A detailed description of the replacements and the optimum binder content (OBC) of mixtures are shown in Table 4.

It can be seen that using RCA in asphalt mixtures as aggregate causes an increase in optimum binder content. OBC increase due to high absorption of the cement paste remaining attached to the surfaces RCA after the recycling process.

\subsection{Indirect tensile fatigue test (ITFT)}

Indirect tensile method is used to evaluate fatigue life of samples in ITFT test. This method involves loading a cylindrical specimen with vertical compressive loads; this generates a relatively uniform tensile stress along the vertical diametrical plane. The type of loading in this method causes two-axis stress in the vertical axis (Braja 1990). Loading and failure of sample in indirect tensile method is shown in Fig. 1.

Stresses created in the centre of the sample because of distributed-load are evaluated with Eqns (1) and (2) (Tangella et al. 1990).

$$
\begin{gathered}
\sigma_{t}=\frac{2 p}{\pi a t}\left[\sin (2 \alpha)-\frac{a}{2 R}\right] ; \\
\sigma_{c}=\frac{-6 p}{\pi a t}\left[\sin (2 \alpha)-\frac{a}{2 R}\right],
\end{gathered}
$$
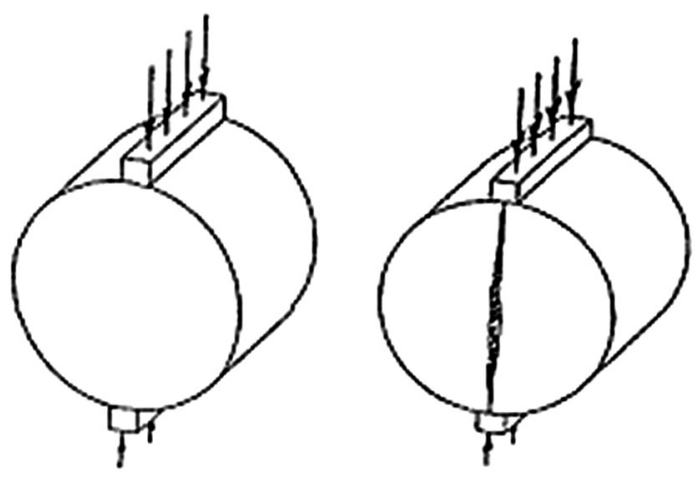

Fig. 1. Position of loading and failure of sample in indirect tensile method (Das, Braja 1990)

\begin{tabular}{|c|c|c|c|c|c|}
\hline \multirow{2}{*}{ Mixture } & \multirow{2}{*}{ Coarse Aggregates } & \multirow{2}{*}{ Fine Aggregates } & \multirow{2}{*}{ Filler } & \multicolumn{2}{|c|}{ OBC \% } \\
\hline & & & & A & B \\
\hline Mix 1 (Control) & $100 \%$ Limestone & $100 \%$ Limestone & Hydrated lime & 5.5 & 5.1 \\
\hline Mix $2\left(\mathrm{RCA}_{25}\right)$ & $100 \%$ Limestone & $\begin{array}{c}65 \% \text { Limestone } \\
35 \% \text { RCA }\end{array}$ & Hydrated lime & 5.7 & 5.2 \\
\hline $\operatorname{Mix} 3\left(\mathrm{RCA}_{50}\right)$ & $100 \%$ Limestone & $\begin{array}{c}\text { 30\% Limestone } \\
70 \% \mathrm{RCA}\end{array}$ & Hydrated lime & 6 & 5.4 \\
\hline Mix $4\left(\mathrm{RCA}_{100}\right)$ & $100 \%$ Limestone & $100 \%$ RCA & Hydrated lime & 6.2 & 5.6 \\
\hline
\end{tabular}

Table 4. RCA replacement values and optimum asphalt content of tested mixes 
where: $p$ is applied load; $a$ is the width of distributedload; $t$ is the thickness of sample; $R$ is the radius of sample; $2 \alpha$ is the degree opposite of the width of distributedload; $\sigma_{t}$ and $\sigma_{c}$ are tensile and compressive stresses in centre of sample.

The fatigue in asphalt mixtures is usually caused by repeated loading. In 1945, Miner offered the mathematical equations to check the process of cumulative failures that are based on liner rule. Miner's supposition, which is used to evaluate failure due to $\mathrm{N}$ repeated load in I stress, is shown in Eq. (3) (Read, Whiteoak 2003):

$$
D=\sum_{i=1}^{m} \frac{n_{i}}{N_{i}} \leq 1,
$$

where: $D$ is failure due to $n$ repeated load in I stress that happened in utilization of roads; $N$ is fatigue life of asphalt mixtures in I stress until failure that evaluated by test on asphalt mixtures in laboratory. According to this supposition, when cumulative failures due to repeated load equal 1 , the fatigue life ends.

Also, in 1965 Monismith offered the Eq. (4) in logarithm scale between fatigue life and $\varepsilon_{t}$ by using linear regression (constant stress mode) (Roque et al. 2002).

$$
N_{f}=a\left(\frac{1}{\varepsilon_{t}}\right)^{b},
$$

where: $N_{f}$ is the number of cycles to failure of the specimen; $\varepsilon_{t}$ is the applied strain and a and $\mathrm{b}$ are the coefficients related to the mixture properties.

The other form of Eq. (4) is Eq. (5), in which fatigue life is expressed terms of stress (constant strain mode):

$$
N_{f}=a\left(\frac{1}{\sigma_{t}}\right)^{b} \text {. }
$$

In this study the fatigue life of the specimens was measured with a Nottingham asphalt tester (NAT) in constant stress mode by applying repeated loads with fixed amplitude along the diametrical axis of the specimen.

The following conditions were considered in fatigue test:

- Sinusoidal loading with frequency equal $1 \mathrm{~Hz}(0.1 \mathrm{~s}$ of loading and $0.9 \mathrm{~s}$ of rest);

- Stress was considered equal to $300 \mathrm{KPa}$;

- The temperatures of test were considered equal to 5 and $40{ }^{\circ} \mathrm{C}$;

- The fatigue criterion was considered creating vertical displacement equals $1 \mathrm{~mm}$.

\section{Results and discussion}

The fatigue life of specimens prepared using different aggregate gradations ( $\mathrm{A}$ and $\mathrm{B}$ ) were determined at loading equals $300 \mathrm{KPa}$ and different temperatures $\left(5\right.$ and $\left.40{ }^{\circ} \mathrm{C}\right)$. The test results are summarized in Figs 2 and 3.

Using regression analysis, the fatigue equations were developed in the form of Monismith's fatigue prediction model (Eq. (4)). For every type of gradation in every two temperatures, the fatigue equations are shown in Table 5.

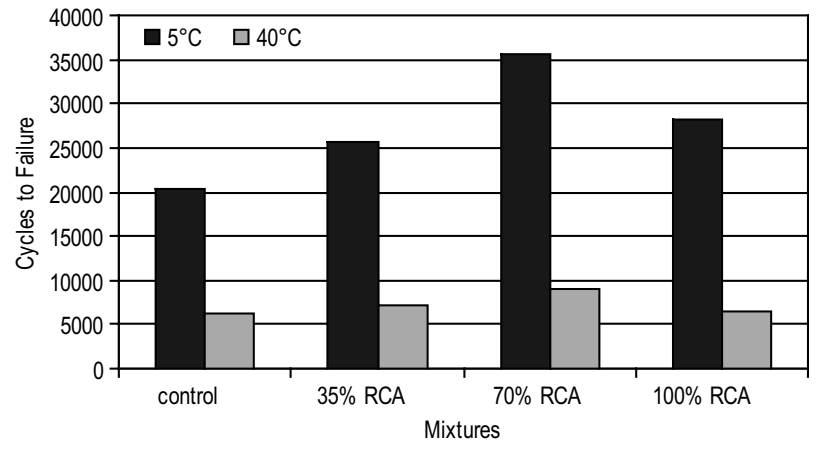

Fig. 2. Number of cycles required for failure vs. mixtures with different RCA contents for gradation type A

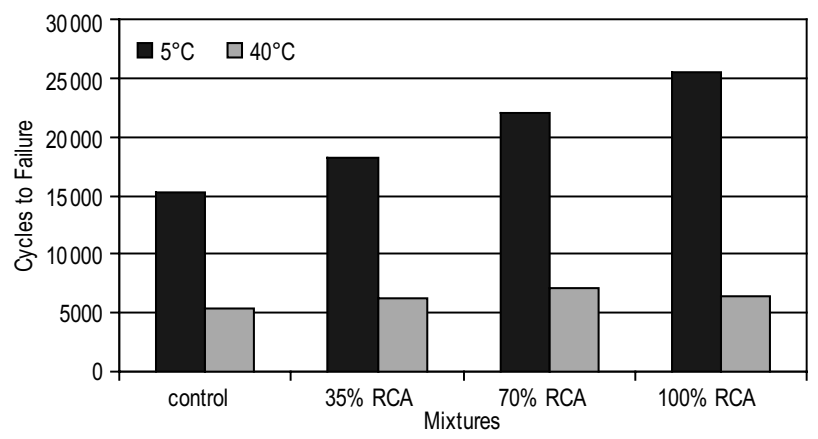

Fig. 3. Number of cycles required for failure vs. mixtures with different RCA contents for gradation type B

Also, the fatigue diagrams for mixtures are shown in Figs 4-7. These diagrams are drawn in a way that the results of the four kinds of mixture by an equal gradation could be compared in a specific temperature.

It was found that replacing up to $100 \%$ of the virgin aggregate with RCA improved the fatigue life of the asphalt mixtures. This can be attributed to more angular recycling concrete aggregate compared to limestone aggregate, as this property causes high frictional and abrasion resistance in asphalt mixtures. Also, the use of RCA as fine aggregate caused changes in particle-size distribution of aggregate mixtures before and after mixing and compaction. These changes cause an increase in the amount of filler, decrease the air void and create a dense graded structure of aggregates interlocked with each other in comparison with a control mixture. In this study an extraction test was used to determine these changes, and a sieve analysis was performed on aggregate obtained from this test. The result showed that after using RCA the amount of fine/filler in two types of gradations was in the optimal limit.

Increasing the RCA creates similar (relatively) process in changes of fatigue life of asphalt mixtures with two types' gradations A and B. As can be seen in gradation type $\mathrm{B}$ compared with type $\mathrm{A}$, the influence of using RCA is lower, because in this type of gradation materials passing sieve \# 4 (size $4.75 \mathrm{~mm}$ ) and amount of RCA as aggregate replacement is less. 
Table 5. Fatigue prediction equations of mixtures

\begin{tabular}{|c|c|c|c|c|c|}
\hline \multirow{2}{*}{ Temperature $\left({ }^{\circ} \mathrm{C}\right)$} & \multirow{2}{*}{ Asphalt type } & \multicolumn{2}{|c|}{$\mathrm{R}^{2}$} & \multicolumn{2}{|c|}{ Fatigue equation } \\
\hline & & Gradation type A & Gradation type B & Gradation type A & Gradation type B \\
\hline \multirow{4}{*}{$5^{\circ} \mathrm{C}$} & Control & 0.951 & 0.92 & $N_{f}=2 \times 10^{8} \varepsilon^{-1.4788}$ & $N_{f}=7 \times 10^{6} \varepsilon^{-1.1271}$ \\
\hline & $35 \% \mathrm{RCA}$ & 0.936 & 0.908 & $N_{f}=5 \times 10^{9} \varepsilon^{-1.716}$ & $N_{f}=3 \times 10^{8} \varepsilon^{-1.4814}$ \\
\hline & $70 \% \mathrm{RCA}$ & 0.965 & 0.919 & $N_{f}=8 \times 10^{12} \varepsilon^{-2.3912}$ & $N_{f}=9 \times 10^{8} \varepsilon^{-1.5794}$ \\
\hline & $100 \% \mathrm{RCA}$ & 0.928 & 0.934 & $N_{f}=3 \times 10^{10} \varepsilon^{-1.8714}$ & $N_{f}=4 \times 10^{9} \varepsilon^{-1.7051}$ \\
\hline \multirow{4}{*}{$40^{\circ} \mathrm{C}$} & Control & 0.947 & 0.948 & $N_{f}=1 \times 10^{8} \varepsilon^{-1.6086}$ & $N_{f}=3 \times 10^{9} \varepsilon^{-2.0012}$ \\
\hline & $35 \% \mathrm{RCA}$ & 0.906 & 0.91 & $N_{f}=3 \times 10^{11} \varepsilon^{-2.4009}$ & $N_{f}=5 \times 10^{10} \varepsilon^{-2.2577}$ \\
\hline & $70 \% \mathrm{RCA}$ & 0.953 & 0.942 & $N_{f}=2 \times 10^{13} \varepsilon^{-2.8294}$ & $N_{f}=9 \times 10^{11} \varepsilon^{-2.5617}$ \\
\hline & $100 \%$ RCA & 0.935 & 0.925 & $N_{f}=2 \times 10^{10} \varepsilon^{-2.1616}$ & $N_{f}=3 \times 10^{11} \varepsilon^{-2.4714}$ \\
\hline
\end{tabular}

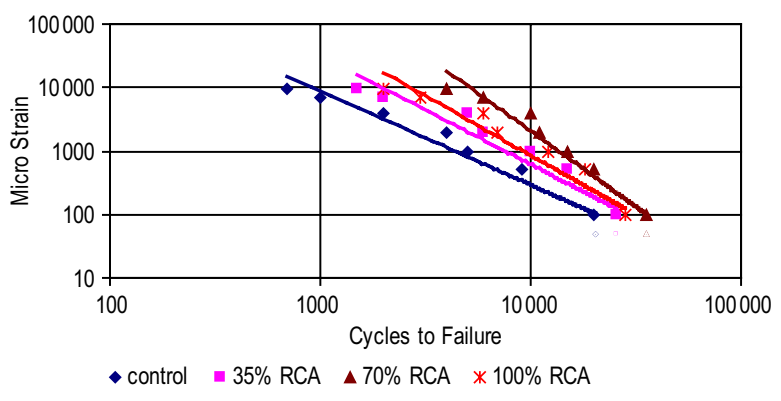

Fig. 4. Comparison of fatigue behavior of different mixes at $5{ }^{\circ} \mathrm{C}$ for gradation type $\mathrm{A}$

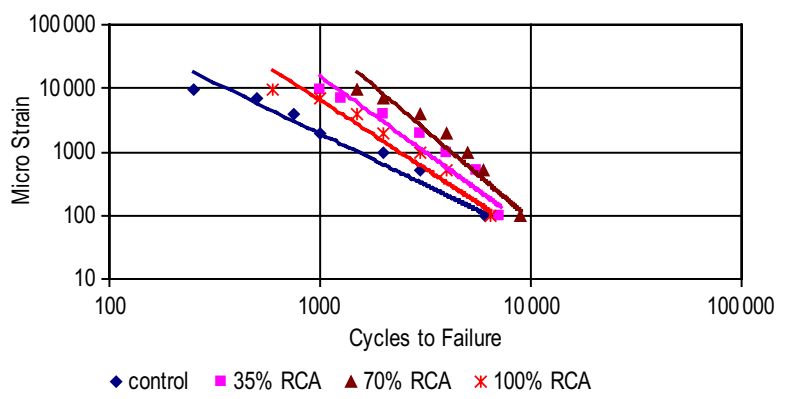

Fig. 5. Comparison of fatigue behavior of different mixes at $40{ }^{\circ} \mathrm{C}$ for gradation type $\mathrm{A}$

Also, by increasing the temperature to $40^{\circ} \mathrm{C}$, fatigue life of all specimens decreases. This behaviour results from the high sensitivity of bitumen in asphalt mixtures to temperature. This confirms the findings of previous research on this issue (Moghadas Nejad et al. 2010; SHRP 1994). Mixtures containing RCA show more sensitivity to temperature increase, compared with control mixture, because of being more the optimized bitumen percentage of these mixtures (containing RCA) compared with the control mixture. Therefore, the results in temperatures of $5{ }^{\circ} \mathrm{C}$ showed that in gradation type A and B the $70 \%$ and $100 \%$ replacement was the optimal replacement level respectively. Also, these replacement result increase in fatigue life of $75 \%$ and $66 \%$, respectively, compared to the control samples. While in temperature's $40{ }^{\circ} \mathrm{C}$ the

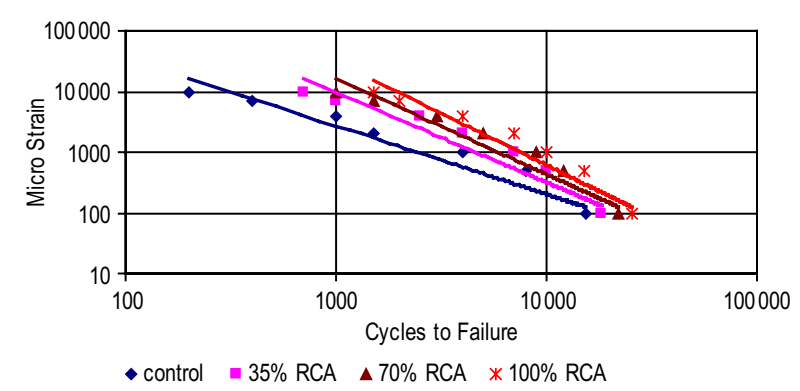

Fig. 6. Comparison of fatigue behavior of different mixes at $5{ }^{\circ} \mathrm{C}$ for gradation type $\mathrm{B}$

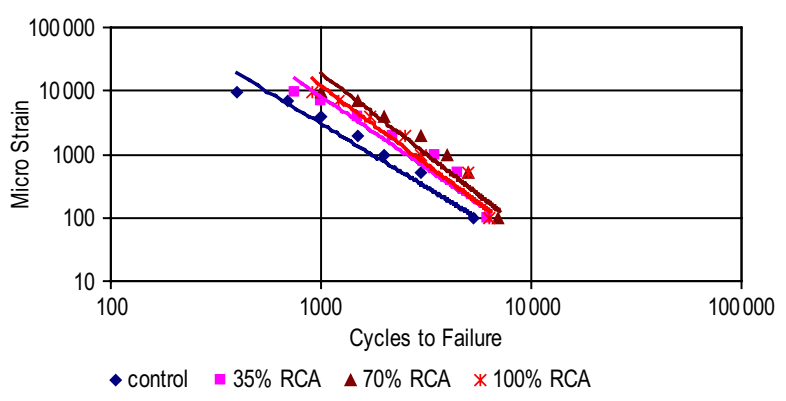

Fig. 7. Comparison of fatigue behavior of different mixes at $40{ }^{\circ} \mathrm{C}$ for gradation type $\mathrm{B}$

$70 \%$ replacement was the optimal replacement level in two type's gradations A and B and these replacements result increase in fatigue life of $45 \%$ and $31 \%$, respectively.

\section{Conclusions}

This investigation was undertaken to evaluate the performance of asphalt concrete mixes using different percentages of RCA and to find the optimal percentages for the replacement of limestone aggregates with RCA. To fulfil this objective, laboratory evaluations of asphalt concrete mixes with different combinations of limestone and RCA aggregates were conducted. Based on the experimental results, the following conclusions can be drawn:

1. An asphalt mixture with finer aggregate gradation has a better fatigue performance than one with coarser ag- 
gregate gradation, which is caused by the denser nature of the former.

2. Using RCA as fine aggregate in hot mix asphalt increases the efficiency of asphalt mixes. It was found that replacing up to $100 \%$ of the virgin aggregate by RCA improved the fatigue life of the asphalt mixtures.

3. In gradation type A influence of using RCA is higher due to finer aggregate of this type of gradation and a greater amount of RCA in the mixture.

4. By increasing the temperature, fatigue life of all specimens decreases. This behaviour results from high sensitivity of bitumen in asphalt mixtures to temperature.

\section{References}

ASTM D1074. 2000. Annual book of ASTM standards, Road and paving materials, Vol. 04.03.

Braja, M. Das. 1990. Principles of geotechnical engineering. $2^{\text {nd }}$ ed. PWS-KENT series in engineering.

Cygas, D.; Mucinis, D.; Sivilevičius, H.; Abukauskas, N. 2011. Dependence of the recycled asphalt mixture physical and mechanical properties on the grade and amount of rejuvenating bitum, The Baltic Journal of Road and Bridge Engineering VI(2): 124-134.

http://dx.doi.org/10.3846/bjrbe. 2011.17

Fonseca, N.; Brito, J.; Evangelista, L. 2011. The influence of curing conditions on the mechanical performance of concrete made with recycled concrete waste, Cement \& Concrete Composites 33(6): 637-643.

http://dx.doi.org/10.1016/j.cemconcomp.2011.04.002

Gilpin, R.; Robinson, J. R.; Menzie, W. D.; Hyun, H. 2004. Recycling of construction debris as aggregate in the MidAtlantic Region, USA, Resources, Conservation and Recycling 42(3): 275-294. http://dx.doi.org/10.1016/j.resconrec.2004.04.006

Hafiang, W. 2001. Fatigue performance evaluation of Westrack asphalt mixtures based on viscoelastic analysis of indirect tensile test, North Carolina State University, Department of Civil Engineering.

Khaled, R. J.; Krizek, F. 1996. Fiber-reinforced recycled crushed concrete as a stabilized base course for highway pavements, Northwestern University, Evanston, IL.

Kou, S. C.; Poon, C. S. 2009. Properties of self-compacting concrete prepared with coarse and fine recycled concrete aggregates, Cement \& Concrete Composites 31(9): 622 627. http://dx.doi.org/10.1016/j.cemconcomp.2009.06.005

Lee, C. H.; Dub, J. C.; Shen, D. H. 2012. Evaluation of precoated recycled concrete aggregate for hot mix asphalt, Construction and Building Materials 28(1): 66-71. http://dx.doi.org/10.1016/j.conbuildmat.2011.08.025

Leite, F. C.; Motta, R. S.; Vasconcelos, K. L.; Bernucci, L. 2011. Laboratory evaluation of recycled construction and demolition waste for pavements, Construction and Building Materials 25(6): 2972-2979. http://dx.doi.org/10.1016/j.conbuildmat.2010.11.105

Mariennfield, M. L.; Smiley, D. 1994. Paving fabrics: the why and the how-to. Geotechnical Fabris Report, 24-29.

Mills-Beale, J.; You, Z. 2010. The mechanical properties of asphalt mixtures with Recycled Concrete Aggregates, Construction and Building Materials 24(3): 230-235. http://dx.doi.org/10.1016/j.conbuildmat.2009.08.046

Moghadas Nejad, F.; Aflaki, E.; Mohammadi, M. A. 2010. Fatigue behavior of SMA and HMA mixtures, Construction and Building Materials 24(7): 1158-1165. http://dx.doi.org/10.1016/j.conbuildmat.2009.12.025

Mucinis, D.; Sivilevicius, H.; Oginskas, R. 2009. Factors determining the in homogeneity of reclaimed asphalt pavement and estimation of its components content variation parameters, The Baltic Journal of Road and Bridge Engineering IV(2): 69-79.

http://dx.doi.org/10.3846/1822-427X.2009.4.69-79

Paranavithana, S.; Mohajerani, A. 2006. Effects of recycled concrete aggregates on properties of asphalt concrete, Resource Conservation Recycling 48(1): 1-12. http://dx.doi.org/10.1016/j.resconrec.2005.12.009

Perez, I.; Pasandín, A. R.; Medina, L. 2012. Hot mix asphalt using C\&D waste as coarse aggregates, Materials and Design 36(4): 840-846. http://dx.doi.org/10.1016/j.matdes.2010.12.058

Poon, C. S.; Chan, D. 2006. Feasible use of recycled concrete aggregates and crushed clay brick as unbound road subbase, Construction and Building Materials 20(8): 578585. http://dx.doi.org/10.1016/j.conbuildmat.2005.01.045

Read, G.; Whiteoak, D. 2003. The Shell Bitumen Handbook. 5 th ed. Thomas Telford Ltd.

Roque, R.; Birgisson, B.; Zhang, Z.; Sangpetngam, B.; Grant, T. 2002. Implementation of SHRP indirect tension tester to mitigate cracking in asphalt pavement and overlay. University of Florida.

Sengoz, B.; Topal, A. 2005. Use of asphalt roofing shingle waste in HMA, Construction and Building Materials 19(5): 337-346.

http://dx.doi.org/10.1016/j.conbuildmat.2004.08.005

Shen, L. Y.; Tam, V. W. Y.; Tam, C. M.; Drew, D. 2004. Mapping approach for examining waste management on construction sites, Journal of Construction Engineering and Management 130(4): 472-481.

http://dx.doi.org/10.1061/(ASCE)0733-9364(2004)130:4(472)

SHRP, A-404. 1994. Fatigue response of asphalt-aggregate mixer, in Strategic highway research program. National Research Council.

Tam, V. W. Y. 2008. Economic comparison of concrete recycling: a case study approach, Resources, Conservation and Recycling 52(5): 821-828. http://dx.doi.org/10.1016/j.resconrec.2007.12.001

Tam, V. W. Y.; Tam, C. M. 2008. Waste reduction through incentives: a case study, Building Research \& Information 36(1): 37-43. http://dx.doi.org/10.1080/09613210701417003

Tangella, S.; Craus, J.; Deacon, J. A.; Monismith. 1990. Summary report on fatigue response of asphalt mixtures, SHRP-A-312, Washington D.C.

Valeria, C. 2010. Mechanical and elastic behaviour of concretes made of recycled-concrete coarse aggregates, Construction and Building Materials 24(9): 1616-1620. http://dx.doi.org/10.1016/j.conbuildmat.2010.02.031

Wong, Y. D.; Sun, D. D.; Lai, D. 2007. Value-added utilization of recycled concrete in hot mix asphalt, Waste Management 27(2): 294-301.

http://dx.doi.org/10.1016/j.wasman.2006.02.001 
Fereidoon MOGHADAS NEJAD. He is an Associate Professor of Pavement Engineering and Director of the Pavement Engineering lab in Department of Civil Engineering at Amirkabir University of Technology, Iran. He holds a PhD degree from The University of Sydney since 1997. His research interests include numerical methods in pavement and railway engineering; computational models for asphalt and concrete pavements; pavement management systems, nondestructive testing; pavement recycling; and pavement materials testing.

Ali Reza AZARHOOSH. He obtained his MSc degree from Guilan University, Iran in 2010. He also obtained his BSc in Civil Engineering from University of Birjand in 2008. His current research mainly covers in asphalt pavement (containing waste aggregates) failures such as rutting, fatigue and moisture damage. His research interests include the Management waste aggregates and resume them as substitute aggregate in asphalt mixtures.

Gholam Hossein HAMEDI. He is studying his PhD degree in the Faculty of Civil \& Environment Engineering at the Amirkabir University of Technology, Tehran, Iran. His research interests are in the area of infrastructure materials. He performs research that relates fundamental material properties related to the mechanisms of damage in asphalt mixtures. Hamedi's research focuses on asphalt pavements performance, microstructure characterization of materials, and moisture damage in asphalt mixtures. 